\title{
Water Shortage in Jordan
}

\section{O. ODEH}

University of Debrecen, Faculty of Engineering, Department of Environmental Engineering, omarrodehh@gmail.com

University of Jordan, Faculty of Engineering, Department of Civil Engineering.

Abstract. Water shortage in Jordan is considered to be one of the main challenges that face the country throughout the years. In this manuscript all aspects of this issue will be highlighted.

In this article, first, the water situation inputs, contests and outputs will be discussed. Secondly, there will be a detailed study about the 'WADI AL-ARAB' Project which is funded by the European Investment Bank and managed by the Yarmouk Water Company, its missions, assets and workflow. Finally, the Improvement of Energy Efficiency in the water sector, project aims, framework, and the major findings expected as a result of these analysis will be highlighted.

This document presents the essential elements of a work that required a long time, an enormous effort and a hard work to collect all the data from several sources such as the Jordanian Ministry of Water and Irrigation (MWI), the Water Authority of Jordan (WAJ) and the European Commission (EU Official Website) and analyze them. Also, all the information listed about "WADI AL ARAB" Project was collected from multiple site visits

\section{Introduction}

As many of us know, lack of water resources is a global issue that many countries are facing including Jordan. To tackle this problem, the causes that led to it should be represented so as to try to find a solution and solve it partially in a way that reduces its effects on the land and the people.

In the arid Middle East, there is always talks of a future water shortage. But, In Jordan, it's already happening. Streams are drying up, and water levels across the desert Arab kingdom are falling. A rationing system has been implemented such that citizens get water from public supplies just one to two days a week. While Jordan's population is rising at approximately $3 \%$ annually, the gap between water supply and demand threatens to widen significantly. By the year 2025, if current trends continue, therefore, the per capita water supply will fall from the current $150 \mathrm{~m}^{3} /$ year to only 91 $\mathrm{m}^{3} /$ year, putting Jordan in the category of having an absolute water shortage [1].

In fact, on a per capita basis, Jordan is the third most water scarce country in the world. Most experts consider countries with a per capita water production below $1000 \mathrm{~m}^{3} /$ year to be water poor countries [2]. In the United States of America, for example, the per capita water supply is $9000 \mathrm{~m}^{3} /$ year.

This paper identifies some of the principal causes of the water shortage in Jordan, discusses the current situation of water supply and demand, and presents some essential elements of reasonable, co-operative, and sustainable water solutions. 


\section{Water Shortage}

The Jordanian Government claims that in comparison to some of Jordan's neighbors, while a Jordanian in $1993 \mathrm{had}$ an annual water share of $200 \mathrm{~m}^{3}$, an Egyptian averaged $1200 \mathrm{~m}^{3}$, a Syrian $1800 \mathrm{~m}^{3}$, and an Israeli $480 \mathrm{~m}^{3}$ as shown in Figure 1 [3].

In the capital Amman, water needs have risen to $300,000 \mathrm{~m}^{3} /$ day. This is $90,000 \mathrm{~m}^{3}$ more than the maximum available daily water levels, which equivalents to a deficit of 35 million cubic meters $\left(\mathrm{Mm}^{3}\right)$ a year. Irrigation water forms $61 \%$ of the total water demands whereas municipal and industrial demands form 31\% and 6\%, respectively as shown in Figure 2 [3]. Jordan is located in an arid-semiarid climatic region where about $80 \%$ of the country receives average precipitation of less than 100 $\mathrm{mm} /$ year and is generally classified as arid. $12.5 \%$ between 100 and $200 \mathrm{~mm} /$ year, 3.8\% between 200 and $300 \mathrm{~mm} /$ year, $1.8 \%$ between 300 and $500 \mathrm{~mm} /$ year, and only $1.3 \%$ receives more than 500 $\mathrm{mm} /$ year. The eastern desert areas receive as little as $50 \mathrm{~mm} /$ year. The precipitation amounts all over Jordan are shown in Figure 3 [3].

Jordan's total rainfall volume in 2004/2005 was about $9304 \mathrm{Mm}^{3}$ of which about $93.9 \%$ evaporates. Only about $3.9 \%$ of precipitation infiltrates to recharge the groundwater. Jordan, which carries the same name as River Jordan, has very little water from river resources because rivers and streams are drying out. Therefore, Jordan mainly depends on rainfall.

Jordan is known to have a large area of desert land on its eastern and southern eastern borders with Iraq and Saudi Arabia respectively. The future prospects for water availability are not good. Jordan's population is expected to rise to 7.3 million by the year 2010, and the resulting gap between water supply and demand is expected to widen significantly. Jordan currently consumes about 941 million cubic meters $\left(\mathrm{Mm}^{3}\right.$ ) of water annually (2005), distributed as $603.5 \mathrm{Mm}^{3}$ for irrigation, $38.4 \mathrm{Mm}^{3}$ for industry, 291.3 $\mathrm{Mm}^{3}$ for household, and 7.8 $\mathrm{Mm}^{3}$ for livestock.

This amount is expected to rise in demand in the near future due to population increasing and economic growth. A critical review of the existing water resources situation in the country reveals that present water problems are attributed to the following reasons:

1. The lack of precipitation has had adverse effects upon the country's amount of surface water, climactic changes have lessened the rainfall.

2. Rapid population growth coupled with increased urbanization and industrialization are leading to the over-exploitation of aquifers and the contamination of water supplies.

3. Inadequate industrial and municipal wastewater treatment capacities; sitting of industrial plants near or immediately upstream from potable supplies; and, overuse and misuse of pesticides, and fertilizers leading to pollution of ground and surface water resources by irrigation drainage. 
4. High water consumption level of the Jordanian people particularly in agriculture has endangered the country's water supply and caused so many shortages. Because of this excess, Jordan's water sources have been drained and dried, as well as polluted.

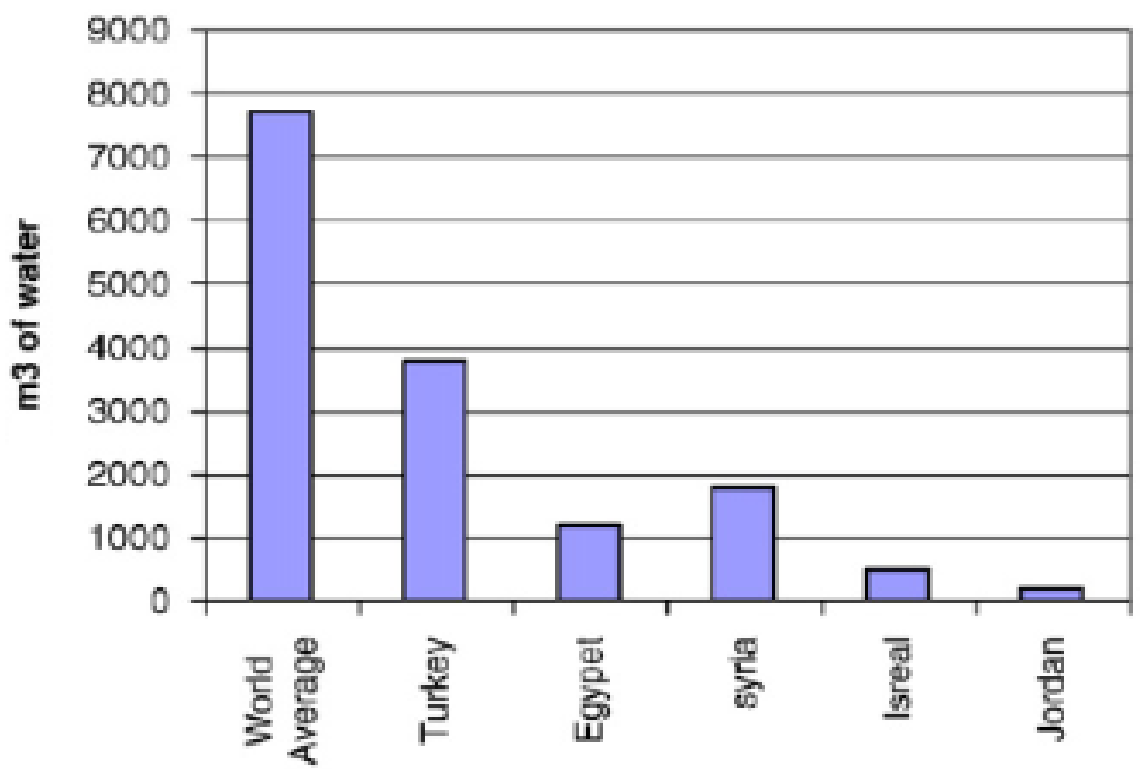

Figure 1. Comparison of annual water share between Jordan and some of Jordan's Neighbors [3].

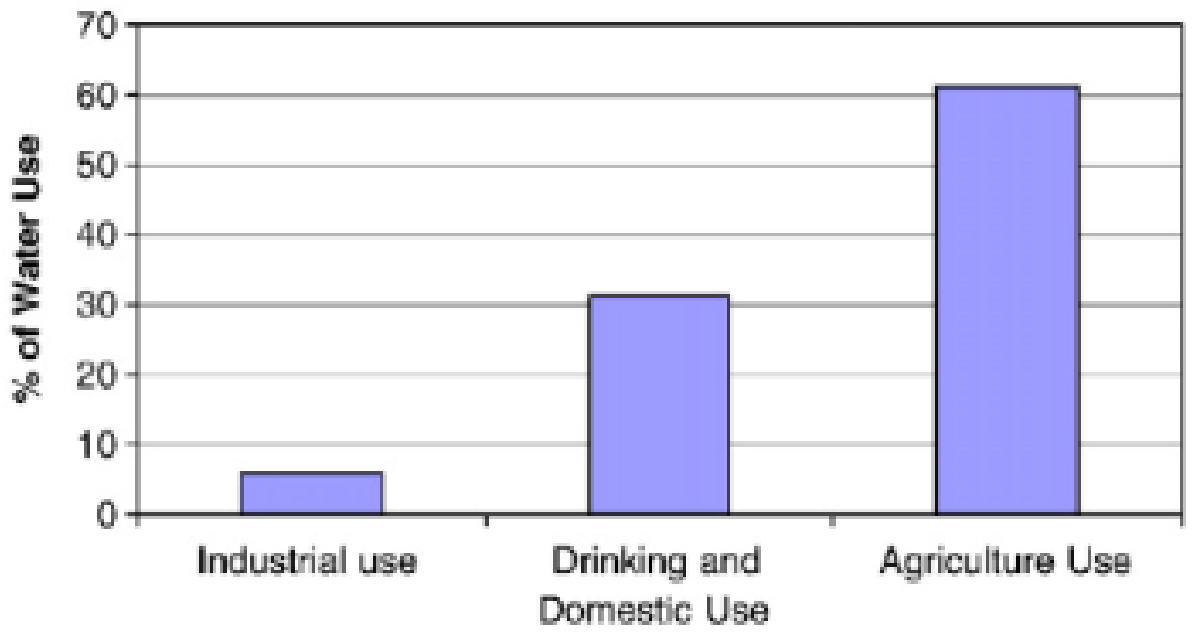

Figure 2. Comparison between industrial use, domestic consumption, and agricultural activities [3]. 


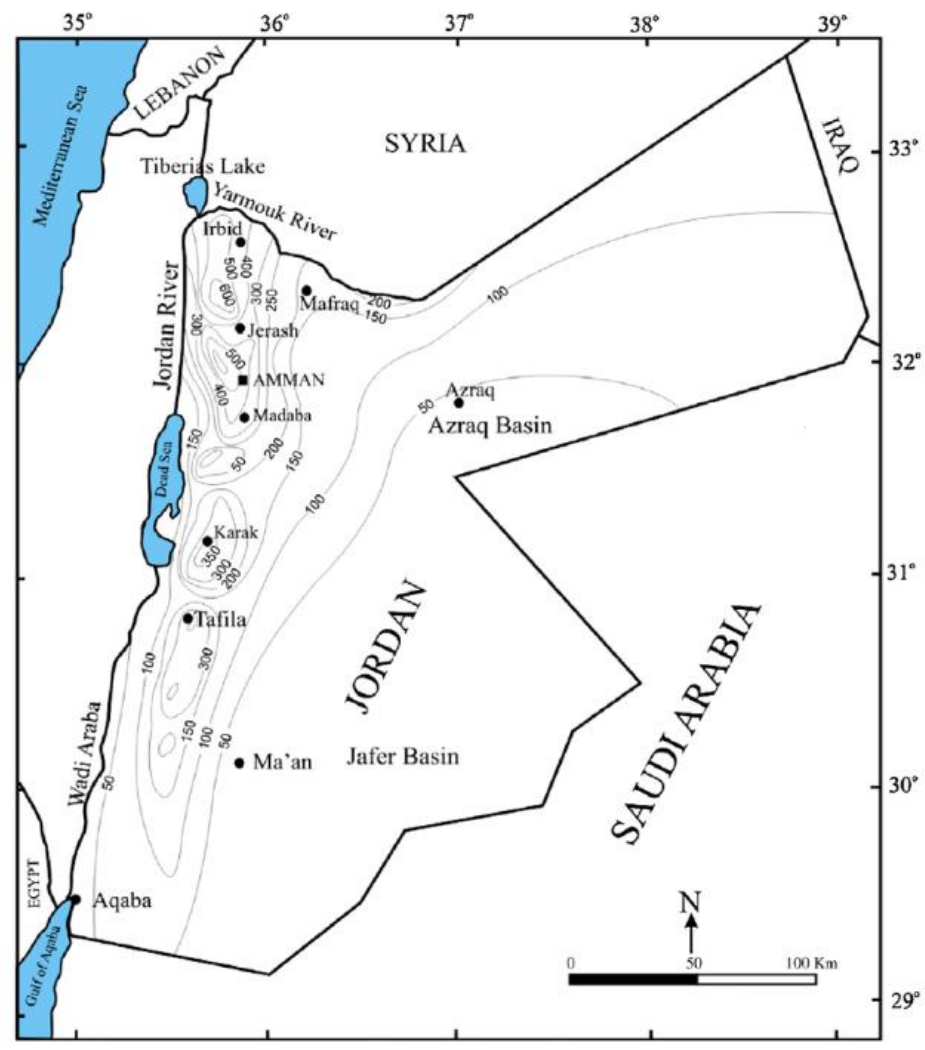

Figure 3. Average distribution of long-term (1938-2005) rainfall in Jordan (After WAJ and Meteorological Department) [3].

\section{Surface Water}

More than three-quarters of Jordan's population lives in urban areas, and this number is rising due to factors such as population growth, the move to cities to search for employment, and the influx of refugees from other countries.

Yet large cities, such as Amman, are often not located near sources of water, which means that water shipments can be costly. But, the water shortage has already placed stress on Jordan's water reserves.

While Jordan relies on groundwater recharge from rainfall for water supplies, precipitation varies each year and over $90 \%$ evaporates before capture.

The main three surface water supply in Jordan are: Jordan River, the Yarmouk River and the Zarqa River. The Jordan River is saline and thus not directly suitable for drinking or irrigation. The River Zarqa receives substantial municipal, industrial and agricultural effluent rendering it unsuitable for domestic or irrigation uses in the dry season. Only during flood periods does the water quality improve. Though the River Yarmouk is reportedly less stressed, it is also a sink for municipal wastewater [4].

Those rivers contribute to about only $28 \%$ of the total water supply in the country. Which makes the groundwater the main water supply in Jordan as shown in Figure 4 [4]. 


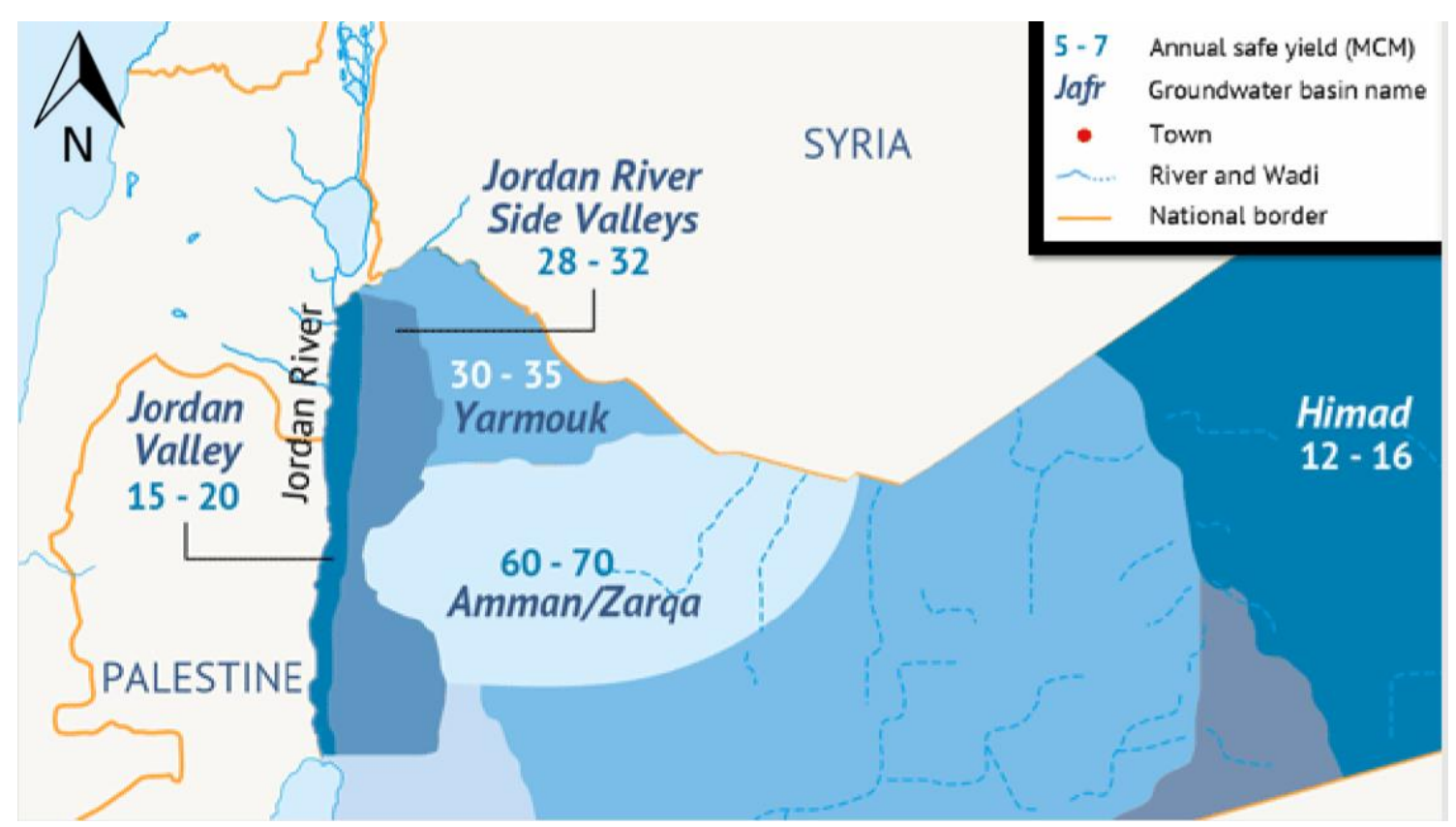

Figure 4. Part of Jordan map shows the different groundwater basins in Jordan [4].

\section{Wadi Al-Arab Project}

The Wadi Al-Arab Water System project is located in the Northwest of Jordan. It is funded by the European Investment Bank and managed by the Yarmouk Water Company. The project seeks to address an acute shortage of water in Irbid, Ajloun, Jerash and Mafraq governorates in the North, which host the majority of Syrian refugees and where water demand gas increased by $40 \%$.

The project will cost $\$ 125$ million where the European Investment Bank is financing $50 \%$ of the project, while the French Development Agency has extended a soft loan to finance another $40 \%$. In addition, a European Union grant is financing the remaining 10\% [5]. The project consists of: 20 working ground wells with an average water production of $2300 \mathrm{~m}^{3} /$ hour, 4 pumping stations and a treatment plant as shown in Figure 5 [6].

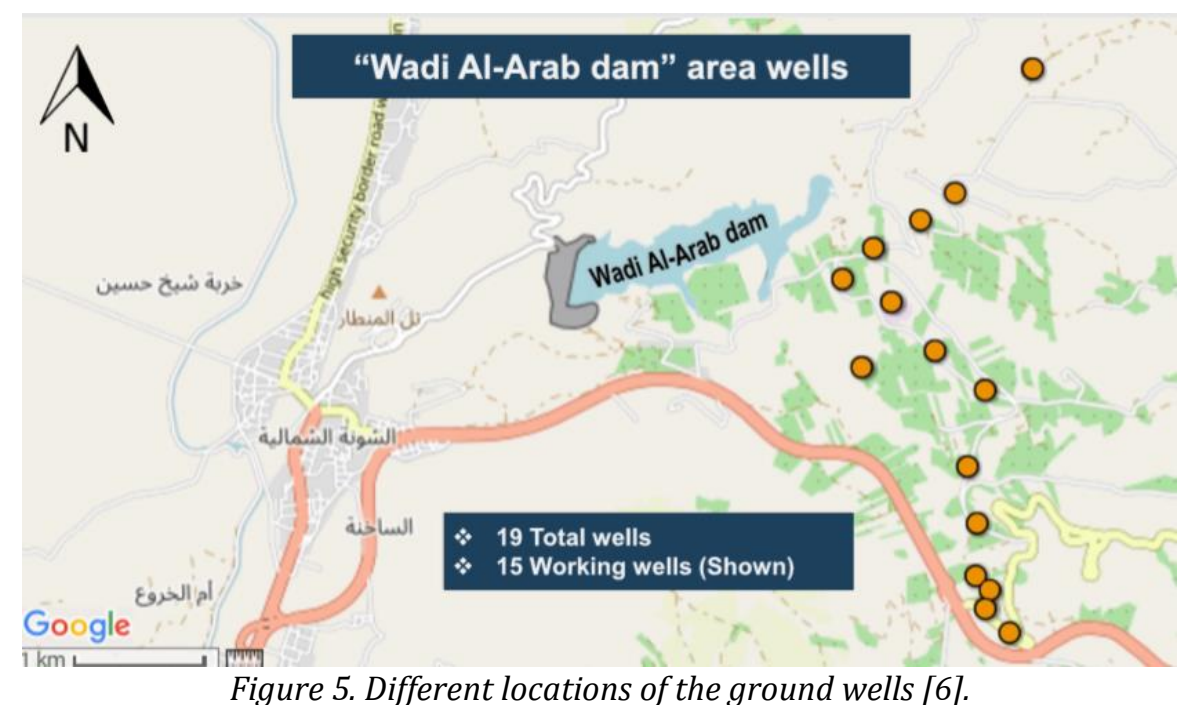

Figure 5. Different locations of the ground wells [6]. 
Moreover, the scope of work consists of the abstraction and treatment of 30 million cubic meters of water per year from the King Abdullah Canal (KAC) to supply the Zabda Reservoir in the City of Irbid (80km North of Amman) Figure 6 [6].

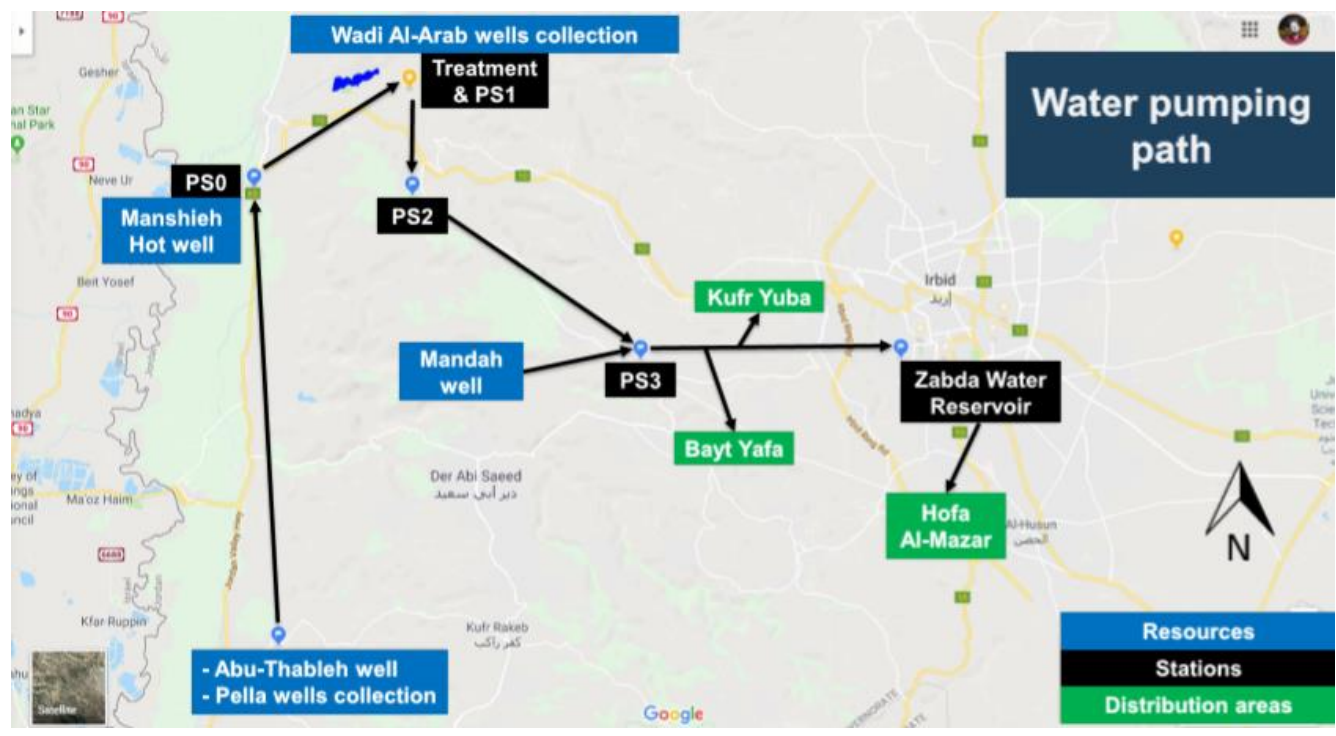

Figure 6. The water pumping path [6].

\section{4. "Improvement of Energy Efficiency in the Water Sector" project}

Since the water sector is Jordan's largest energy consumer, The Yarmouk Water Company aims to develop and integrate an energy management system within Jordan's water sector which contribute to increase energy efficiency and better cost recovery. This energy is used mainly in two processes, pumping water from the ground wells and through pumping stations. The project work includes the replacement of all mechanical and electrical work at certain stations and wells, in addition to the rehabilitation of related civilian facilities SCADA control system is going to be installed in Wells 3A, 5 and 9. Also, in the pumping stations PS0 and PS1. The expected saving of energy consumption is about 50 million KWh / year, i.e. 7\% of the total annual energy consumption of the water authority [7].

\section{Basics of a sustainable solution}

A. Development of new supplies of water Governments and civil engineers have historically been successful at tapping new sources of water, but nearly all the low-cost options for doing this have been exhausted in Jordan. Since all the rivers and aquifers are fully exploited, few options are left for developing new sources of drinking water.

B. Fortunately, desalination; the energy intensive process of converting brackish water or seawater to fresh water has been proven and continues to be made more cost effective. Many plants exist in Saudi Arabia, United Arab Emirates, Kuwait, and the USA. The cost of producing drinking water from seawater has decreased from $\$ 1.50$ to possibly $\$ 0.63$ per $\mathrm{m}^{3}$ (at the plant gate, under ideal conditions) [8]. As Amman is above sea level and distant 
from the seacoast, the cost to its residents would (in the absence of a co-operative water exchange program with its neighbors) have to include additional pumping and transport costs of roughly $\$ 0.25$ to $\$ 0.35$ per $\mathrm{m}^{3}$.

C. Producing the fresh water by transporting and processing, seawater from the Mediterranean or Red Sea [9].

D. The processing of wastewater for reuse in the agricultural sector is a viable option and already in use (and being further developed) in the Jordan Valley. In addition to reducing the demand on freshwater. The cost to treat and deliver water for agricultural needs depends on the crop and quality required, and on the proximity of the farm to the city.

E. Reduction of water demand.

- Since agriculture is the largest water-using sector in Jordan then implementing proper irrigation technologies like sprinkler systems, drip irrigation, subsurface irrigation systems and plastic greenhouses improve water savings during hot seasons [10].

- Domestic applications represent $30 \%$ of total demand. Greywater can be reused to replace partially fresh water used in flush toilets, while using proper showerheads will reduce demand on fresh water. Also, capturing and storing rainwater from roofs can reduce the demand on the fresh water.

- flush toilets, while using proper showerheads will reduce demand on fresh water. Moreover capturing and storing rainwater from roofs can reduce the demand on fresh water for other domestic purposes for example gardening purposes.

- A comprehensive program of educating the public in Jordan on the water issue could gain their support for fair terms for the final status talks, as well as their assistance in maintaining the quality of shared waters. If the growing water crisis is to be mitigated, the public will have to be part of the solution [11].

\section{Conclusions}

The main reason for the severe water shortage in Jordan is simply the lack of natural surface water resources: rivers and lakes. Moreover, recent severe drought periods have further complicated the water shortage problem. Currently, the economy of Jordan as developing country cannot support the full implementation of sea water desalination as fresh water source.

Two large water projects should be implemented to provide Jordan with an abundance of water for domestic and agricultural use by 2020. 
A. The first project is a multi-billion-dollar undertaking to link the Dead Sea and the Red Sea with a $325 \mathrm{~km}$ canal. By implementing this project hydropower energy would be generated, this power could be utilized to desalinate sea water to amend it as drinkable water.

B. The second project is the DISI Water Conveyance Project, the main objective is to convey additional water to the Greater Amman Area from the Disi Aquifer. The Disi-Mudawarra to Amman Water Conveyance System will result in a reliable water supply to Amman especially during the summer. This project has been on the shelf for many years, postponed due to a lack of funding. However, due to pressing water needs, serious efforts have been made successfully to implement the proposal. Disi is a fossil water aquifer extending from the southern edge of the Dead Sea in Jordan to Tabuk in northwest Saudi Arabia. The Disi project will have an indirect effect on the quality of wastewater, which in turn will lead to better quality water to be used for irrigation as a replacement for valuable freshwater.

This study presents some strategic initiative for facilitating and institutionalizing long-term progress in the environmental sphere: promotion of public awareness of and participation in water protection programs, construction of a comprehensive legal framework for water management, giving sectoral priority to water conservation and slowing Jordan's rapid population growth.

Methodology for follow up to contract the planned schemes for sustainable water solutions are:

A. Collect data creating data bank.

B. Conducting researches and studies.

C. Funding support, training program, technique assistance.

D. Public awareness through education, publicity (press, seminars, leaflets etc.).

E. Organized land use planning.

F. Executing a long-term responsibility to promote confidence for water policy.

G. Encourage active and future oriented research and development process.

\section{Recommendations}

A. Intensive capturing of rainwater through harvesting, the use of micro- and macro-dams, assessing the existing water harvesting structures by hydrological studies, analytical tests and determining the sediments amount in these structures. This research shows that the harvest of surface runoff for groundwater recharge is a viable approach to partially resolve the water shortage problem in Jordan and rehabilitating the ecosystems damaged by groundwater mining. It is suggested to construct micro-dams along the major waterways, in order to store floodwater during winter seasons, to use it again in the summer farming 
seasons, as complementary irrigation water, instead of the flowing aimlessly through abandoned, uncultivated areas. This way is considered efficient water harvesting of rainwater; this action will benefit the farmers, and raise the national food sufficiency.

B. Desalination of seawater and wastewater.

C. Employing proper treatment technologies to treat industrial wastewater containing heavy metals. The country should also upgrade the existing wastewater treatment plants for better and efficient utilization of the reclaimed water.

D. Treated wastewater should be the main source for irrigating the plants. If no measures are taken a severe water shortage will occur within few years, this will mean need to reduce the agriculture activity plans.

E. Implementing proper maintenance to water distribution network to reduce the losses of drinkable water through leakage.

F. Importation of water from neighboring countries.

G. Severe water shortages required to impose a rationing program in distributing water to end users.

However, all these are subject to cost-benefit analyses and geopolitical constraints. Water conflicts in Jordan may not remain open much longer. Responsible individuals, organizations, and nations should act now.

\section{References}

[1] O.R. Al-Jayyousi, M.R. Shatanawi, An analysis of future water policies in Jordan using decision support, Systems Water Resources Development 11 (1995) 315.

[2] PRB, World Population Data Sheet. Demographic Data and Estimates for the Countries and Regions of the World, PRB, Washington, DC, USA, 1998.

[3] WAJ and Meteorological Department, Open File, 2005.

[4] Abu-Taleb, F. Maher, Environmental management in Jordan: problems and recommendations, Environmental Conservation 21 (1994) 35-40.

[5] Madad action document $7^{\text {th }}$ ob west Irbid wastewater network construction Ref. (2018)82144

[6] Yarmouk Water Company documents.

[7] The GIZ study Improvement of Energy Efficiency of WAJ, http://www.iee-jordan.net/en/home. 
International Journal of Engineering and Management Sciences (IJEMS) Vol. 4. (2019). No. 4

DOI: 10.21791/IJEMS.2019.4.31.

[8] UNIDO, Guidelines for Infrastructure development through Build-Operate-Transfer (BOT) Projects, UNIDO, Vienna, 1996.

[9] Masahiro Murakami, Alternative strategies in the inter-state regional development of the Jordan Rift Valley, in: Glantz, Kobori (Eds.), Central Eurasian Water Crisis, United Nations University, Tokyo, Japan, 1998.

[10] Lester Brown, Tough Choices: Facing the Challenge of Food Scarcity, W. W. Norton \& Company, NYC and London, 1996.

[11] Gill Ringland, Scenario Planning: Managing for the Future, John Wiley \& Sons Ltd, Chichester, West Sussex, England, 1998, p. 131. 